\title{
A scientific note on the comparison of airborne volatiles produced by commercial bumble bee (Bombus impatiens) and honey bee (Apis mellifera) colonies
}

\author{
Jason R. Graham ${ }^{1}$, Mark J. Carroll ${ }^{2}$, Peter E. A. Teal ${ }^{2}$, James D. Ellis ${ }^{1}$ \\ ${ }^{1}$ Entomology Nematology Department, University of Florida, PO Box 110620, Bldg. 970 Natural Area Dr., Gainesville, \\ FL 32611, USA \\ ${ }^{2}$ Center for Medical, Agricultural, and Veterinary Entomology, Agricultural Research Service, Chemistry Research Unit, U.S. \\ Department of Agriculture, 1600 Southwest 23rd Drive, Gainesville, FL 32608, USA
}

Received 12 March 2012 - Revised 30 June 2012 - Accepted 19 July 2012

volatile / Bombus impatiens / bumble bee / Apis mellifera / honey bee / olfaction

Investigators have shown (Stanghellini et al. 2000; Spiewok and Newman 2006; Hoffman et al. 2008) that commercial bumble bee (Bombus impatiens Cresson, Hymenoptera: Apidae) colonies can serve as potential alternative hosts for the small hive beetle (SHB, Aethina tumida Murray, Coleoptera: Nitidulidae), a honey bee pest (Lundie 1940; Neumann and Elzen 2004; Ellis and Hepburn 2006). Using olfactory choice tests, Graham et al. (2011) found that SHB attraction to bumble bee colonies is chemically mediated. Since SHBs are attracted to bumble bee and honey bee colonies, we expected the volatile profiles produced by bumble bee and honey bee colony components to be similar. To test this, airborne volatiles produced by bumble bee and honey bee adults, brood (eggs, larvae, and pupae), honey, stored pollen ( $=$ bee bread), and wax were collected and analyzed.

In June 2007, two commercial bumble bee ( $B$. impatiens) quads (= eight colonies; Koppert Biological Systems, Inc., Romulus, MI) were established at the University of Florida's Bee Biology Unit in

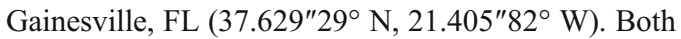
quads consisted of four bumble bee colonies containing a reproductive queen, 200-250 workers, brood, and nesting material. Eight queenright honey bee colonies were housed in typical Langstroth style

Corresponding author: J.R. Graham, jgraham@ufl.edu

Manuscript editor: Monique Gauthier equipment at the University of Florida's Bee Biology Unit in Gainesville, FL.

Volatiles were collected from colony components using methods modified from Suazo et al. (2003). The colony components (adult bees, brood, honey, pollen, and wax) were extracted from eight bumble bee and eight honey bee colonies. The samples were placed in glass volatile collection chambers $(3.8 \mathrm{~L})$ by component and colony at the USDA-ARS Center for Medical, Agricultural, and Veterinary Entomology (CMAVE, Gainesville, FL). All volatile collections were conducted in a controlled environmental chamber maintained without light and at an ambient temperature of $\sim 33{ }^{\circ} \mathrm{C}$. Charcoal-filtered and humidified air, controlled by carboloy flowmeters, was passed through the volatile collection chambers and into SuperQ filters at a rate of $0.5 \mathrm{~L} / \mathrm{min}$. All component volatiles were collected for $14 \mathrm{~h}$ with the exception of brood volatiles that were collected for $7 \mathrm{~h}$. The abbreviated time frame for volatile collection of brood was intended to avoid stressing the unattended brood, recognizing the fact that brood may still be stressed in the absence of adult workers. Adult bees were provisioned with a cotton wick saturated with a $50 \%$ sugar water solution and an autoclaved steel mesh platform on which the adults could crawl to minimize stress. Volatiles trapped on the SuperQ filters were extracted by eluting the filter with $500 \mu \mathrm{L}$ of methylene chloride. These samples were pooled by component and bee type and stored in a $-70{ }^{\circ} \mathrm{C}$ freezer (Revco Scientific, Inc., Asheville, NC) at CMAVE until use. 
The pooled volatile samples were analyzed for both bee types by component at the CMAVE using a HP-6890 gas chromatograph (GC, Hewlett Packard, Palo Alto, CA) equipped with a HP-1 column (30 $\mathrm{m} \times 0.25 \mu \mathrm{m}, \mathrm{J} \& \mathrm{~W}$ Scientific, Folsom, CA). The column was linked to an HP 5973 mass spectrometer using electron impact mode $(70 \mathrm{eV}$, Agilent, Palo Alto, CA) with the gas carried by helium. Volatile compounds were identified by comparison of retention times with available synthetic standards (SigmaAldrich, St. Louis, MO) and mass spectra with mass spectra libraries (NIST, University of Gottenburg Chemical Ecology, Sweden).

Contrary to our hypothesis, we found that there is a high level of variability between the volatiles collected from bumble bee and honey bee colony components as well as volatiles collected from whole colonies. Only 6 of 147 detected volatiles were common to both bee species (Table I).

2-Heptanone, present among volatiles emitted by adults of both bee types (Table I), is known to be produced from mandibular glands of worker honey bees, acts as a "forage marking pheromone," and can attract/repel guard honey bees (Vallet et al. 1991). Limolene is the only volatile common to the brood of both species. Limonene, along with 2-heptanone, heptanal, pinene, octanal, terpenine, methyl benzoate, nonanal, and decanal, was found to be honey bee hive volatiles capable of being detected by sensillae on the SHB antennae in Gas Chromatography Electro-Antennographic Detection (GC-EAD) bioassays (Torto et al. 2007a).
The compounds 1-phenoxy-2-propanol and butylated hydroxytoluene were detected in the honey volatiles of both species and this is the first report of these compounds being associated with either species. Butylated hydroxytoluene has been used extensively in the food industry as a food antioxidant additive (Branen 1975) and may have been present in the nesting materials or artificial diets provided to the colonies. Volatiles collected from bumble bee and honey bee wax contained the shared compounds 2nonanone and nonanal, while volatiles collected from bumble bee and honey bee pollen contained only the shared compound nonanal (Table I). Nonanal was found by Saleh et al. (2007) to be a chemosensory cue, left behind by Bombus terrestris at food locations, nest locations, and neutral areas (areas neither associated with food locations or with nest locations). Nonanal and 2-nonanone were used in wind tunnel studies where SHBs were found to be attracted to a blend of compounds which were collected from adult honey bees; nonanal also was detected by SHB and honey bees in GC-EAD (Torto et al. 2005, 2007a, b).

In conclusion, commercial bumble bee and honey bee colonies, while similar enough to host the same and similar pests and pathogens, remain different regarding their volatile profiles. It is likely that the volatile profiles of honey bees and bumble bees are complex, varying with temperament, bee health, and other circumstances. This study provides an initial comparison of the chemical ecology of commercial bumble bees and honey bees. With an understanding of the chemical ecology associated with both types of

Table I. Chemical compounds of volatiles collected from bumble bee and honey bee colony components

\begin{tabular}{|c|c|c|c|c|c|c|c|c|}
\hline \multirow[b]{2}{*}{$\begin{array}{l}\text { Chemical } \\
\text { compound }\end{array}$} & \multirow[b]{2}{*}{ Quality } & \multirow[b]{2}{*}{$\begin{array}{l}\text { Molecular } \\
\text { weight (amu) }\end{array}$} & \multirow[b]{2}{*}{ CAS number } & \multirow[b]{2}{*}{ Adults } & \multicolumn{4}{|c|}{ Colony component } \\
\hline & & & & & Brood & Honey & Pollen & Wax \\
\hline 2-Heptanone & 81 & 114.104 & 000110-43-0 & $\mathrm{x}$ & & & & \\
\hline Limonene & 90 & 136.125 & $000138-86-3$ & & $\mathrm{x}$ & & & \\
\hline 2-Nonanone & 90 & 142.128 & $000821-55-6$ & & & & & $\mathrm{x}$ \\
\hline Nonanal & 98 & 142.136 & 000124-19-6 & & & & $\mathrm{x}$ & $\mathrm{x}$ \\
\hline 1-Phenoxy-2-propanol & 96 & 152.084 & $000770-35-4$ & & & $\mathrm{x}$ & & \\
\hline $\begin{array}{l}\text { Butylated } \\
\text { hydroxytoluene }\end{array}$ & 94 & 220.183 & $000128-37-0$ & & & $\mathrm{x}$ & & \\
\hline
\end{tabular}

Quality refers to how closely the compound matches the result from the GCMS library search (with 100 being an absolute match and 0 being no match at all). Only like chemical compounds discovered in similar components with a quality rating $\geq 80$ that have been verified by the respective synthetic standard chemical compounds are reported herein 
bee colonies, a tool may be found to help conserve these important pollinators and control the damage caused by SHBs and other nest invaders.

\section{Note scientifique sur la comparaison des composés volatiles libérés dans l'air entre les colonies du bourdon commercial (Bombus impatiens) et celles de l'abeille (Apis mellifera)}

Eine wissenschaftliche Notiz über den Vergleich von flüchtigen Substanzen, die von kommerziellen Hummelvölkern (Bombus impatiens) und Völkern der Honigbiene (Apis mellifera) in die Luft abgegeben werden

\section{REFERENCES}

Branen, A.L. (1975) Toxicology and biochemistry of butylated hydroxyanisole and butylated hydroxytoluene. J. Am. Oil Chem. Soc 2(52), 59-63

Ellis, J.D., Hepburn, H.R. (2006) An ecological digest of the small hive beetle (Aethina tumida), a symbiont in honey bee colonies (Apis mellifera). Insectes Soc 53, 8-19

Graham, J.R., Ellis, J.D., Carroll, M.J., Teal, P.E.A. (2011) Aethina tumida (Coleoptera: Nitidulidae) attraction to volatiles produced by Apis mellifera (Hymenoptera: Apidae) and Bombus impatiens (Hymenoptera: Apidae) colonies. Apidologie 3(42), 326-336

Hoffman, D., Pettis, J.S., Neumann, P. (2008) Potential host shift of the small hive beetle (Aethina tumida) to bumblebee colonies (Bombus impatiens). Insectes Soc. 2(55), 153-162

Lundie, A.E. (1940) The small hive beetle (Aethina tumida). Entomol. Series 3 220, 30. Union of South Africa Science Bulletin Department of Agriculture and Forestry
Neumann, P., Elzen, P.J. (2004) The biology of the small hive beetle (Aethina tumida, Coleoptera: Nitidulidae): Gaps in our knowledge of an invasive species. Apidologie 35, 229247

Saleh, N., Scott, A.G., Bryning, G.P., Chittka, L. (2007) Distinguishing signals and cues: bumblebees use general footprints to generate adaptive behavior at flowers and nest. Arthropod-Plant Interact 2(1), 119-127

Spiewok, S., Neumann, P. (2006) Infestation of commercial bumblebee (Bombus impatiens) field colonies by small hive beetles (Aethina tumida). Ecol. Entomol. 31, 623628

Stanghellini, M.S., Ambrose, J.T., Hopkins, D.I. (2000) Bumble bee colonies as potential alternative hosts for the small hive beetle (Aethina tumida Murray). Am. Bee. J. 140, 71-75

Suazo, A., Torto, B., Teal, P.E.A., Tumlinson, J.H. (2003) Response of the small hive beetle (Aethina tumida) to honey bee (Apis mellifera) and beehive-produced volatiles. Apidologie 34, 525-533

Torto, B., Suazo, A., Alborn, H., Tumlinson, J.H., Teal, P.E.A. (2005) Response of the small hive beetle (Aethina tumida) to a blend of chemicals identified from honeybee (Apis mellifera) volatiles. Apidologie 36, 523-532

Torto, B., Boucias, D.G., Arbogast, R.T., Tumlinson, J.H., Teal, P.E.A. (2007a) Multitrophic interaction facilitates parasite-host relationship between an invasive beetle and the honey bee. Proc. Nat. Acad. Sci. USA 104, 83748378

Torto, B., Arbogast, R.T., Alborn, H., Suazo, A., van Englesdorp, D., Boucias, D.G., Tumlinson, J.H., Teal, P.E.A. (2007b) Composition of volatiles from fermenting pollen dough and attractiveness to the small hive beetle, Aethina tumida, a parasite of the honey bee, Apis mellifera. Apidologie 38, 380-389

Vallet, A., Cassier, P., Lensky, Y. (1991) Ontogeny of the fine structure of the mandibular glands of the honeybee (Apis mellifera L.) workers and the pheromonal activity of 2heptanone. J. Insect Physiol. 11(37), 789-804 